\title{
The effectiveness of uterine packing combined with topical tranexamic acid for the management of primary postpartum hemorrhage
}

\author{
Maysara M. Abdulridha; Dhamya S. Alharoon ${ }^{2}$; Jubran K. Hassan³ \\ 1. CABOG.FICMS, MRCOG; Department of obstetrics \& gynecology, College of Medicine- University of Basrah \\ 2. CABOG; Al Basrah hospital for maternity and childhood \\ 3. Ph.D clinical pharmacy; Department of clinical pharmacy; college of pharmacy; university of Basrah
}

Received:24.04.2020

Accepted:15.12.2020

\begin{abstract}
Objectives: the aim of the study is to identify the effectiveness of adding topical tranexamic acid to uterine pack to control primary postpartum hemorrhage PPH compared to uterine packing alone.

Methods: the study included 30 women with intractable primary PPH after vaginal deliveries due to uterine atony in whom the conventional local pathway of management of PPH had failed to control bleeding. In 15 women (the case group), uterine pack impregnated with 20 ml of tranexamic acid $(1 \mathrm{gm} / 10 \mathrm{ml})$ was used to control bleeding and compared to 15 women (the control group) in whom uterine pack without tranexamic acid was used, outcome studied include the need for further surgical intervention and the need for blood product transfusion.

Results: although uterine packing impregnated with TXA was successful in controlling bleeding in 13 women out of 15(86.7\%) compared to 10 out of 15 cases $(66.7 \%)$ in women who underwent uterine packing without TXA, however; the difference between effectiveness of each method is statistically insignificant. The requirement for blood product transfusion was less in TXA group.

Conclusion: topical uterine TXA increase the efficiency of uterine tamponade to control PPH, and may decrease the need for more invasive surgical intervention as hysterectomy
\end{abstract}

Keywords: tranexamic acid, uterine packing, postpartum hemorrhage

\section{Corresponding to:}

Maysara M. Abdulridha, CABOG.FICMS, MRCOG;

Department of obstetrics \& gynecology, College of Medicine-

University of Basrah

$\triangle \quad$ Maysaram1979@gmail.com

Phone No.: +9647712045056

\section{Introduction}

Postpartum hemorrhage (PPH) is generally defined as blood loss in excess of $500 \mathrm{ml}$ after vaginal delivery or $>1000 \mathrm{ml}$ after cesarean delivery ${ }^{(1)}$.There is an increase in the incidence of PPH across the world, and it is one of the commonest direct causes of maternal mortality worldwide $^{(2,3)}$. Uterine atony is the commonest cause of primary postpartum hemorrhage ${ }^{(4)}$.In addition to death, it may result in severe morbidity including disseminated intravascular coagulation, adult respiratory distress syndrome, shock, infertility, and Sheehan syndrome ${ }^{(5)}$.

\section{Tranexamic acid in PPH}

Tranexamic acid (TXA) is a synthetic lysineanalogue antifibrinolytic agent, it binds to the lysine binding sites on plasminogen which inhibits plasmin formation .In high concentrations it inhibits plasmin activity and fibrinogenolysis directly, also Tranexamic acid may act through an anti-inflammatory mechanism by inhibiting plasmin-mediated enhancement of complement, monocytes, and neutrophils and it may also act through platelet function improvement ${ }^{(6)}$. WHO recommend intravenous tranexamic acid administration within three hours of PPH regardless the mode of 
delivery and whether the bleeding is due to genital tract trauma or uterine atony ${ }^{(7)}$. However, high doses of systemic TXA is associated with seizure and thromboembolism, the actual risk of thromboembolism including pulmonary embolism remains uncertain ${ }^{(8,9)}$. Recently local application of tranexamic acid have been used in cardiothoracic and orthopedic surgery $^{(10,11)}$. Topical TXA has minimum or no risk of thromboembolism compared to systemic route, hence , the idea of intracavitary $\mathrm{TXA}^{(9)}$.

\section{Uterine tamponade}

Uterine tamponade whether packing or balloon is a good alternative to surgical intervention in patients with severe obstetrical hemorrhage that failed to response to the conventional therapy ${ }^{(12)}$ - the aim of the study is to identify the effectiveness of adding topical tranexamic acid to uterine pack to control primary PPH compared to uterine tamponade alone.

\section{Methods}

This is a case-control study, held in AL-Basra hospital for maternity and childhood through a period extended from August 2017 till December 2019.

Agreement of the ethical committee of medical college of Basra was obtained to carry out the study.

A total of 30 women were recruited in the study, those women had intractable primary PPH after vaginal deliveries due to uterine atony with estimated blood loss of more than $1500 \mathrm{ml}$,in whom the conventional local pathway of management had failed to control bleeding which include: bladder catheterization ,uterine message ,bimanual compression, oxytocic drugs including IV ergometrin(0.5-1mg) ,oxytocin infusion(40 IU in $500 \mathrm{ml}$ normal saline $125 \mathrm{ml} /$ hour) , misopristol $800 \mathrm{mg}$ rectally and intravenous tranexamic acid $1 \mathrm{gm}$ within 3 hours of onset of hemorrhage, so they were transferred to the operative theatre where examination under general anesthesia was performed to exclude retained product of conception, cervical or vaginal trauma and rupture uterus.Those patients were subdivided into 2 groups by simple randomization without blindness (because the management was held by two of the investigators on separate cases with no third party to ensure blindness) :

Case group(15 cases): in this group of women a sterile gauze of $10 \mathrm{~cm}$ wide and 1 meter long folded in layers and impregnated with $20 \mathrm{ml}$ of tranexamic acid(two ampoules of cyklokapron ${ }^{\mathrm{TM}}$ $1 \mathrm{gm}, 100 \mathrm{mg} / \mathrm{ml}$ ) was inserted in the uterus using two sponge foceps :one to hold the anterior lip of the cervix and the other to introduce the gauze inside the uterus, the packing was kept for 12-24 hours with oxytocin infusion 20 IU in $1 \mathrm{~L}$ of normal saline over 6 hours and antibiotic cover(IV ceftriaxone and metronidazole for the first 24 hours followed by oral cefuroxime and metronidazole for 4 days), with continuous observation of vital signs and fundal height to exclude concealed hemorrhage, with replacement with blood products as required.

Control group which involve 15 women in whom the same pathway of management as cases was followed, however, uterine packing was done without tranexamic acid impregnation. The outcome in both groups were compared including failure to control bleeding and requirement for surgical intervention, need for blood transfusion and maternal mortality.

Lapratomy was performed for women in whom uterine packing failed to control bleeding , uterine artery ligation, internal iliac artery ligation and B-Lynch suture were done and lastly if these failed to control bleeding, hysterectomy was done (uterine artery embolization is unavailable in our locality). 
The Medical Journal of Basrah University

(2020); 38(2): 104-108

\section{Results}

Table 1 shows non-significant differences in age and parity between the two groups, the majority of women were in the fourth decade and multiparous , $46.7 \%$ of women in control group were grandmultipara compared to $26.7 \%$ in the case group, $40 \%$ of women in both groups had augmented labour .

Table 1 characteristics of women in both groups

\begin{tabular}{|c|c|c|c|}
\hline & $\begin{array}{l}\text { Control group } \\
\mathrm{N}=15\end{array}$ & $\begin{array}{l}\text { Study group } \\
\qquad \mathbf{N}=15\end{array}$ & $P$ value \\
\hline Age & $32.6 \pm 5.9$ & $31.8 \pm 5.8$ & 0.8293 \\
\hline Parity & $3.9 \pm 1.6$ & $3.4 \pm 1.6$ & 0.3783 \\
\hline$\leq 4$ & $8(53.3 \%)$ & $11(73.3 \%)$ & \\
\hline $\begin{array}{l}>4 \text { (grand } \\
\text { multipara) }\end{array}$ & $7(46.7 \%)$ & $4(26.7 \%)$ & 0.4486 \\
\hline \multicolumn{4}{|c|}{ Types of labour } \\
\hline spontaneous & $5(33.3 \%)$ & $6(40 \%)$ & \multirow{3}{*}{0.8897} \\
\hline augmented & $6(40 \%)$ & $6(40 \%)$ & \\
\hline induced & $4(26.7 \%)$ & $3(20 \%)$ & \\
\hline
\end{tabular}

there was insignificant difference in blood loss between both groups $(1946.7 \pm 356.3$ and 1926.6 \pm 357.5 in control and case group respectively). as shown in Table 2 ,

Women who received topical tranexamic acid had required significantly less transfusion of packed RBC and fresh frozen plasma(FFP) compared to the control group $(2.5 \pm 1.6$ pint of packed $\mathrm{RBC}$ versus $4.3 \pm 2.8$ in the control group and $0.7 \pm 0.9$ units of FFP versus $2 \pm 1.8$ units in the control group).

In the case group, failure to control vaginal bleeding was reported in only two women(13.3\%) and surgical intervention was necessary, both cases ended with subtotal hysterectomy, while in those who had uterine packing without tranexamic acid (control group), uterine packing combined with topical tranexamic acid for the management of primary postpartum hemorrhage

five cases $(33.3 \%)$ required lapratomy: three cases end with hysterectomy to control bleeding and in the other two case bleeding was controlled by uterine artery ligation combined with B-Lynch suture.

The average duration of uterine packing was less in the case group compared to control but without statistical significance.

During the study, two patients (6.7\%) developed non-significant pyrexia that didn't exceed $38.2^{\circ} \mathrm{C}$ on the fourth day postpartum and resolved after 2 days (one patient from each group) and there were no cases of concealed hemorrhage in both groups.

Table 2 blood products transfusion and surgical intervention in both groups.

\begin{tabular}{|c|c|c|c|}
\hline & $\begin{array}{l}\text { Control group } \\
\qquad \mathrm{N}=15\end{array}$ & $\begin{array}{l}\text { Study } \\
\text { group } \\
\mathrm{N}=15\end{array}$ & P value \\
\hline Blood loss (mls) & $1946.7 \pm 356.3$ & $\begin{array}{c}1926.6 \pm \\
357.5\end{array}$ & 0.8791 \\
\hline \multicolumn{4}{|c|}{ Blood products transfused } \\
\hline $\begin{array}{l}\text { Packed RBC } \\
\text { (pint) average }\end{array}$ & $4.3 \pm 2.8$ & $2.5 \pm 1.6$ & 0.0414 \\
\hline 1 pint & $1(6.7 \%)$ & $5(33.3 \%)$ & \multirow{2}{*}{0.1709} \\
\hline$>1$ pint & $14(93.3 \%)$ & $10(66.7 \%)$ & \\
\hline $\begin{array}{l}\text { FFP (Units) } \\
\text { average }\end{array}$ & $2 \pm 1.8$ & $0.7 \pm 0.9$ & 0.0219 \\
\hline $\begin{array}{l}\text { No. of patient } \\
\text { required FFP }\end{array}$ & $11(73.3 \%)$ & $7(46.7 \%)$ & 0.2636 \\
\hline $\begin{array}{c}\text { No. of patients } \\
\text { received platelets }\end{array}$ & $4(26.7 \%)$ & $2(13.3 \%)$ & 0.6481 \\
\hline $\begin{array}{l}\text { Duration of pack } \\
\text { dwelling (hours) }\end{array}$ & $17.9 \pm 5.8$ & $15.2 \pm 7$ & 0.2915 \\
\hline $\begin{array}{c}\text { Surgical } \\
\text { intervention }\end{array}$ & $8(53.3 \%)$ & $1(6.7 \%)$ & 0.0168 \\
\hline
\end{tabular}

Table 3 show logistic regression for different variable including age, parity, blood products transfused to the patients; only parity shows positive significant effect on failure of uterine packing and the need for surgical intervention (increase parity associated with increased rate of surgical intervention); however, there is 
The Medical Journal of Basrah University

(2020); 38(2): 104-108

insignificant difference in parity between case and control groups as shown in table 1 .

Table 3 logistic regression analysis data for evaluation of the effect of different variables on the need for surgical intervention in the case group

\begin{tabular}{|l|l|l|l|l|}
\hline $\begin{array}{l}\text { Outcome need } \\
\text { for surgical } \\
\text { intervention }\end{array}$ & $\begin{array}{l}\text { Regression } \\
\text { coefficient }\end{array}$ & P-value & $\begin{array}{l}\text { Odd } \\
\text { ratio }\end{array}$ & $\begin{array}{l}\text { Odd ratio } \\
\text { Confidence } \\
\text { interval }\end{array}$ \\
\hline Constant & -10.19 & 0.0005 & & \\
\hline Age & $0.1708-$ & 0.1439 & 0.843 & $\begin{array}{l}0.6339 \text { to } \\
1.121\end{array}$ \\
\hline Parity & 2.572 & 0.0324 & 13.09 & $\begin{array}{l}0.4413 \text { to } \\
388.3\end{array}$ \\
\hline $\begin{array}{l}\text { Blood Lost } \\
\text { (mls) }\end{array}$ & $-2.91 \times 10^{-4}$ & 0.1626 & 0.999 & $\begin{array}{l}0.9946 \text { to } \\
1.005\end{array}$ \\
\hline $\begin{array}{l}\text { Blood received } \\
\text { (pints) }\end{array}$ & 0.05442 & 0.1258 & 1.056 & $\begin{array}{l}0.4159 \text { to } \\
2.681\end{array}$ \\
\hline FFP (units) & 2.339 & 0.7510 & 10.37 & $\begin{array}{l}0.7187 \text { to } \\
149.7\end{array}$ \\
\hline $\begin{array}{l}\text { Needs for } \\
\text { Platelets }\end{array}$ & -3.10 & 0.5858 & 0.0451 & $\begin{array}{l}3.6 \times 10^{-4} \text { to } \\
5.64\end{array}$ \\
\hline
\end{tabular}

$\mathrm{P}<0.05$ considered as significant

\section{Discussion}

The few studies concentrated on topical tranexamic acid in PPH usually used uterine balloon which is not always available especially in our locality, so in our study we studied the effectiveness of uterine packing with topical tranexamic acid to control PPH.

In our study, there was insignificant difference in total blood loss between the two groups despite the fact that topical tranexamic acid is supposed to arrest bleeding earlier, this could be due to blood loss prior to insertion of uterine pack as the average duration between onset of vaginal bleeding and uterine packing in the control and case group was 34 and 37 minute respectively, however, the need for transfusion of blood products including packed $\mathrm{RBC}$ and fresh frozen plasma was less in those who received topical Tranexamic acid because in these cases there is dual haemostatic action: direct pressure on the placental bed and the pharmacological action of Tranexamic acid that inhibit plasmin formation uterine packing combined with topical tranexamic acid for the management of primary postpartum hemorrhage

and (in high doses) plasmin action which in turn reduced ongoing bleeding and thus depletion of blood component, this result is in agreement with the study of Nahla $W$. and Hany $F^{(13)}$

The success rate in the group of women who underwent uterine packing with topical tranexamic acid with no need for further surgical intervention was $86.7 \%$,while in the control group, uterine packing without topical tranexamic acid had controlled bleeding in $66.7 \%$ of women, however, this difference doesn't reach statistical significance, this indicate that the antifibrinolytic effect of local tranexamic acid combined to mechanical pressure is superior to mechanical effect alone, this result is in harmony with the case report presented by Kinugasa M. etal ${ }^{(9)}$,.however, in their cases they used intrauterine balloon wrapped with gauze impregnated with tranexamic acid. Also this result is in harmony with the study of Nahla W.etal,where topical tranexamic acid was effective in prevention of postpartum haemorrhage in cases with placenta $\operatorname{previa}^{(13)}$.

\section{Conclusion:}

Topical uterine Tranexamic acid increases the efficiency of uterine tamponade to control PPH, and may decrease the need for more invasive surgical intervention as hysterectomy.

\section{Acknowledgment}

staff and member of department of gynecology and obstetrics in Al Basrah maternity \&childhood hospital.

\section{References}

1. ACOG Practice Bulletin No. 76. Postpartum hemorrhage. Obstet Gynecol 2006;108:1039-48. 2. Bateman, Brian T., Berman, Mitchell F.,MPH ${ }^{\dagger}$; Riley, Laura E., Leffert, Lisa R. The 
The Medical Journal of Basrah University

(2020); 38(2): 104-108

Epidemiology of Postpartum Hemorrhage in a Large, Nationwide Sample of Deliveries. Anesthesia \& Analgesia, May 2010; Volume 110(5): 1368-1373.

3.Sam Ononge,Florence Mirembe,Julius Wanda bwa ,Oona M. R. Campbell.Incidence and risk factors for postpartum hemorrhage in Uganda. Reproductive Health, 2016;13:38

4. Muhammad Muzzammil Edhi, Hafiz Muhammad Aslam, Zehra Naqvi, Haleema Hashmi. "Post partum hemorrhage: causes and management"biomed central journal. biomed central journal, 2013 Jun 18.

5. ACOG Practice Bulletin: Clinical Management Guidelines for ObstetricianGynecologists Number 76, postpartum hemorrhage. Obstet Gynecol. 2006 Oct;108(4):1039-47.

6. Maj Richard Reed, Tom Woolley. Uses of tranexamic acid. Continuing Education in Anaesthesia, Critical Care \& Pain,2015;15:32-37

7. WHO updates recommendation on intravenous tranexamic acid for the treatment of postpartum haemorrhage.Nov 2017

8. Irene Lecker, Dian-Shi Wang, Paul D. Whissell, Sinziana Avramescu, David Mazer ,Beverley A. Orser. Tranexamic acid-associated seizures: Causes and treatment. annals of neurology journal, November 2015 uterine packing combined with topical tranexamic acid for the management of primary postpartum hemorrhage

9. Masato Kinugasa, Hanako Tamai, Mayu

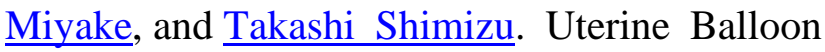
Tamponade in Combination with Topical Administration of Tranexamic Acid for Management of Postpartum Hemorrhage._Case Reports in Obstetrics and Gynecology, Volume 2015, Article ID 195036, 4 pages Case Report

10. A.Dell'Amore,G.Caroli,A.Nizar et al., Can topical application of tranexamic acid reduce blood loss in thoracic surgery?A prospective randomised double blind investigation. Heart,Lung and Circulation,2012;21:706-710

11. J.Wong, A. Abrishami,H. El Beheiry et al.,Topical application of tranexamic acid reduces postoperative blood loss in total knee arthroplasty: a randomized, controlled trial. The Journal of Bone and Joint Surgery-American Volume,2010;92:2503-2513

12. Gulfishan Haq, Subhana Tayyab. Control of Postpartum and Post Abortal Haemorrhage with Uterine Packing.JPMA ,2005;55:369

13. Nahla W. Shady, Hany F. Sallam. Adjunctive IV tranexamic acid versus topical tranexamic acid application of the placental bed for prevention of postpartum hemorrhage in women with placenta previa: a randomized controlled trial. International journal of reproduction, contraception, obstetrics and gynecology.2017; $6: 12$ 